Meta

Journal des traducteurs

Translators' Journal

\title{
Foreign Language Learning Strategies and Consecutive Interpreting Achievement: An Exploratory Study on Taiwanese Interpreting Students
}

\section{Yung-Nan Chiang et Daniel Steve Villarreal}

Volume 58, numéro 1, avril 2013

URI : https://id.erudit.org/iderudit/1023814ar

DOI : https://doi.org/10.7202/1023814ar

Aller au sommaire du numéro

Éditeur(s)

Les Presses de l’Université de Montréal

ISSN

0026-0452 (imprimé)

1492-1421 (numérique)

Découvrir la revue

Citer cet article

Chiang, Y.-N. \& Villarreal, D. S. (2013). Foreign Language Learning Strategies and Consecutive Interpreting Achievement: An Exploratory Study on Taiwanese Interpreting Students. Meta, 58(1), 146-164.

https://doi.org/10.7202/1023814ar
Résumé de l'article

Il a été souvent observé que les étudiants en interprétation ne possédaient pas une connaissance suffisante de leurs langues de travail pour répondre aux attentes de leur future profession, principalement pour l'interprétation de leur langue A vers leur langue B. Toutefois, aucune recherche empirique n'a montré que les stratégies d'apprentissage de la langue B étaient en rapport avec leurs performances en interprétation. Afin de combler cette lacune, la présente étude explore la relation entre les stratégies d'apprentissage de la langue étrangère (l'anglais) et les compétences en interprétation chez un groupe d'étudiants de premier cycle à Taïwan. Les stratégies d'apprentissage chez les participants ont été évaluées au moyen de l'échelle SILL (Strategy Inventory for Language Learning) d'Oxford et leurs compétences, au moyen de leurs notes dans les cours d'interprétation du mandarin vers l'anglais. Les données ont été analysées à partir de statistiques descriptives et de corrélations. Les résultats suggèrent qu'il existe une corrélation positive entre les stratégies d'apprentissage de la langue étrangère et les compétences en interprétation, que l'échelle SILL soit analysée de façon globale, en sous-échelles ou au cas par cas. Ces résultats nous permettent finalement de proposer des stratégies d'apprentissage et des avenues de recherches.
Ce document est protégé par la loi sur le droit d'auteur. L’utilisation des services d'Érudit (y compris la reproduction) est assujettie à sa politique d'utilisation que vous pouvez consulter en ligne.

https://apropos.erudit.org/fr/usagers/politique-dutilisation/ 


\title{
Foreign Language Learning Strategies and Consecutive Interpreting Achievement: An Exploratory Study on Taiwanese Interpreting Students
}

\author{
YUNG-NAN CHIANG \\ National Taipei University of Technology, Taipei, Taiwan \\ yungnan2@yahoo.com
}

DANIEL STEVE VILLARREAL

National Defense Medical Center, Taipei, Taiwan

interpreterman@aol.com

\section{RÉSUMÉ}

Il a été souvent observé que les étudiants en interprétation ne possédaient pas une connaissance suffisante de leurs langues de travail pour répondre aux attentes de leur future profession, principalement pour l'interprétation de leur langue A vers leur langue B. Toutefois, aucune recherche empirique n'a montré que les stratégies d'apprentissage de la langue $B$ étaient en rapport avec leurs performances en interprétation. Afin de combler cette lacune, la présente étude explore la relation entre les stratégies d'apprentissage de la langue étrangère (l'anglais) et les compétences en interprétation chez un groupe d'étudiants de premier cycle à Taïwan. Les stratégies d'apprentissage chez les participants ont été évaluées au moyen de l'échelle SILL (Strategy Inventory for Language Learning) d'Oxford et leurs compétences, au moyen de leurs notes dans les cours d'interprétation du mandarin vers l'anglais. Les données ont été analysées à partir de statistiques descriptives et de corrélations. Les résultats suggèrent qu'il existe une corrélation positive entre les stratégies d'apprentissage de la langue étrangère et les compétences en interprétation, que l'échelle SILL soit analysée de façon globale, en sous-échelles ou au cas par cas. Ces résultats nous permettent finalement de proposer des stratégies d'apprentissage et des avenues de recherches.

\begin{abstract}
Although it has been frequently noted that interpreting students' command of their working languages has not been solid enough to meet the challenge of interpreting, especially the challenge of interpreting from an A language to a B language, there has been no empirical research into whether their $B$ language learning strategies are related to their interpretation achievement. This exploratory study filled this gap in the literature by investigating the relationship between foreign language (English) learning strategies and consecutive interpreting achievement among a group of undergraduate interpreting students in Taiwan. The participants' learning strategies were assessed by Oxford's Strategy Inventory for Language Learning (SILL), while their achievement was measured by their semester grades in Mandarin-English interpreting classes. Descriptive statistics and correlation analyses were used to analyze the data. The results showed that learning strategies had significant positive correlations with interpreting achievement, regardless of whether the SILL was analyzed in terms of the overall scale, its subscales, or its individual items. Based on the results, implications for offering learning strategies training to students are discussed and directions for future research are suggested.
\end{abstract}




\section{MOTS-CLÉS/KEYWORDS}

anglais langue seconde, stratégies d'apprentissage, interprétation consécutive, compétence, Taïwan

English as a Foreign Language (EFL), learning strategies, consecutive interpreting, achievement, Taiwan

\section{Introduction}

Interpreting is a skill built on a solid command of at least two languages. Ideally, interpreting students should undertake interpreting training only after they have perfected their command of their working languages; however, this desired goal is not always achieved, particularly with respect to the B languages (Gile 1995; 2009). The issue of $\mathrm{B}$ language deficiencies is even more pronounced among interpreting students with Mandarin Chinese as their A language and English as their B language: Despite years of learning English as a foreign language in school, few Taiwanese students have used English as a medium for communication in the real world, and this problem is further aggravated by the interpreting problems arising from the immense differences between Mandarin and English (for detailed analyses, see Setton 1993; 1999; Chang and Schallert 2007; Chang and Wu 2010; 2011). While there are plenty of suggestions in the literature regarding how to enhance interpreting students' B languages (e.g., Donovan 2004; 2005; Lim 2005; Monti, Bendazzoli et al. 2005; Wu 2001), there has been little empirical research on how interpreting students improve their own B languages.

An exception is Chang and Wu's (2011) study of foreign language needs of 26 conference interpreting trainees pursuing advanced degrees in Mandarin-English interpretation at two major graduate institutes in Taiwan. As part of their investigation into the foreign language (English) needs of their participants, Chang and Wu (2011) used an open-ended question to elicit the students' English learning strategies, and found a mismatch between the students' perceived English deficiencies and their English learning strategies. Despite the fact that productive skills, especially speaking, were identified by the students as their greatest failing, most students tried to improve their English proficiency by engaging in a wide range of receptive skills, such as reading, listening to radio programs or watching TV programs.

Although Chang and Wu's (2011) study shed some light on the probable cause of interpreting students' insufficient command of English as a foreign language by showing that inappropriate uses of foreign language learning strategies might be to blame, there are several limitations in their study. Foremost, they used only an openended question on their questionnaire to elicit the students' English learning strategies instead of a validated measurement instrument. The absence of a validated instrument in their study compromised the validity, reliability and generalizability of their findings. In addition, although they suggested that the students might not be able to effectively ameliorate their spoken English ability for the purpose of Mandarin-to-English interpreting by using these language learning strategies, they did not investigate the relationship between interpreting students' English learning strategies and their interpreting achievement.

In light of these gaps, this study crossed the disciplinary divide between second language acquisition (SLA) and interpreting studies by drawing on SLA research into 
second and foreign language (L2) learning strategies in order to investigate interpreting students' foreign language learning strategies as well as the relationship between their strategy use and interpreting achievement. Oxford's (1990) theory of L2 learning strategies was used as a theoretical framework in this study. According to Oxford (1990), learning strategies are "specific actions taken by the learner" to facilitate their learning (Oxford 1990: 8); she classified L2 learners' learning strategies into direct and indirect strategies; the former includes memory, cognitive, compensation strategies, while the latter includes metacognitive, affective, and social strategies. For that reason, the Strategies Inventory for Language Learning (SILL) developed by Oxford (1990) was used as a measurement instrument. Two research questions guided this study:

1. What English learning strategies do interpreting students in Taiwan report using? What are the general trends and patterns of strategy use for these students?

2. Is there a relationship between English learning strategy use and interpreting achievement as measured by their semester grades in Mandarin-English consecutive interpreting courses?

\section{Literature Review}

Since Rubin's (1975) and Naiman, Frolich et al.'s (1978) pioneering works on the learning strategies of good language learners, L2 learning strategy researchers have long been interested in the relation of strategy use to language performance. In this line of research, three types of language performance measures have been commonly used, including achievement tests (performance in relation to a specific curriculum), proficiency tests (i.e., performance linked to general standards of competence but not a specific curriculum), and language task behaviors (i.e., performance on specific L2 learning tasks). Regardless of which type of language performance measure has been used, except for some occasional conflicting findings, decades of L2 learning strategy studies have generally shown a significant positive relationship between strategy use and language performance (Green and Oxford 1995; Lan and Oxford 2003). A significant positive linkage between strategy use and proficiency in different language skills was also found: Oxford and Nyikos's (1989) survey of 1200 American foreign language students found that higher L2 proficiency self-ratings in speaking, listening, and reading were linked to higher frequency of strategy use. They concluded that "a causal relationship actually existed between proficiency self-ratings and strategy use" (Oxford and Nykos 1989: 295).

Different groups of strategies were found to have different relationships with language performance (for a review, see Oxford 2004). For instance, in several studies on English as a Foreign Language (EFL) students, cognitive strategies were significantly associated with proficiency (Ku 1995; Park 1994). In Mullins's (1992) study of Thai EFL students and in Oxford and Ehrman's (1995) study on American learners of different target languages, compensation strategies were significantly related to foreign language proficiency. Metacognitive strategies were significant correlates of EFL students' proficiency (Dreyer and Oxford 1996; Mullins 1992). Both social strategies and affective strategies were significantly and positively related to proficiency in Dreyer and Oxford's (1996) study on South African EFL students and in Oxford and Ehrman's (1995) study on learners of a variety of target languages; 
however, Watanabe (1990) found social and affective strategies were not related to Japanese EFL students' self-ratings of English proficiency and a significant negative correlation was found between affective strategies and language test scores in Mullins' (1992) study of Thai EFL students. Memory strategies were found to have significant positive relationship with L2 proficiency in learners of Japanese (Kato 1996, cited in Oxford 2004), ${ }^{1}$ but have a significant negative relationship with test performance in grammar and vocabulary (Purpura 1997). In addition, whereas language performance was linked to more than one strategy groups in most studies, Ehrman and Oxford's (1995) research among 885 adults in an intensive program yielded a different finding: Cognitive strategy group was the only SILL category significantly correlated with one of their proficiency ratings.

Some individual learning strategies were linked to language performance as well. As cited in Oxford and Crookall (1989), McGroarty's study on American learners of elementary Spanish and Japanese found that language achievement was linked to several classroom strategies indicating cognitive strategy use, such as repeating new forms and taking notes on new words; the same study also found several strategies were linked to the pretest scores, including socializing with native language speakers, taking risks with the new language, and exposing oneself to the target language through the media. On the other hand, Abraham and Vann (1987) and Vann and Abraham (1990) found that successful and unsuccessful learners often used the same strategies, but with the difference lying in the degree of flexibility and appropriateness of how these strategies were mobilized to meet the task demands at hand.

Several studies focusing on Taiwanese L2 students have generally yielded results supporting the detecting of a significant positive relationship between strategy use and language performance. For instance, both Lin (1999) and Wang (2001) examined senior high school EFL students' listening strategies and listening proficiency, and produced similar results - a significant positive relationship between strategy use and listening proficiency. Lin (1999) further found that more proficient listeners' uses of listening strategies, such as comprehension monitoring and problem-solving, were more frequent and flexible than the strategies of less proficient learners, who relied primarily on native-language cues. More recently, Lai's (2009) investigation of college EFL students found that English proficiency level had a significant effect on strategy choice and use across all six strategy categories as measured by the SILL.

In summary, decades of L2 learning strategies research have shown that although some studies have produced different results, the majority of the strategy studies have found a significant positive linkage between strategy use and language performance. However, all of the existing studies have been conducted among regular L2 learners. No research has as yet undertaken examining the relationship between interpreting students' L2 learning strategies and interpreting performance despite the fact that interpreting students are L2 learners as well. Hence, this study aimed to fill the gaps in the literature by taking an interdisciplinary approach to examining interpreting students' L2 learning strategies and the probable link between their strategy use and interpreting achievement. 


\section{Method}

\subsection{Participants}

The participants included 105 students enrolled in Mandarin-English consecutive interpreting classes at four technical universities in Taiwan. Among these universities, two were public universities, whereas the other two were private universities. All of the students were seniors; they took interpreting courses as part of the requirement for their bachelor's degree in Applied Foreign Language (English). ${ }^{2}$ Their age averaged 21.3. Of the participants, $75 \%(n=78)$ were female, and $25 \%(n=27)$ were male. Their formal schooling in English averaged 9.8 years.

\subsection{Instruments}

Two instruments were used, including a background questionnaire and Yang's (1992) modified Chinese version of Oxford's (1990) SILL. The background questionnaire collects the students' biographic information such as age and gender. Regarding the measure of English learning strategies, the Chinese SILL is essentially the same as the original SILL, except some minor differences in the items, e.g., the Chinese SILL has 49 items while the original SILL has 50 items. Like the original SILL, the Chinese SILL is a Likert-scaled measurement that assesses two classes of learning strategies with six subscales, including direct strategies (memory strategies, cognitive strategies and compensation strategies) and indirect strategies (metacognitive strategies, affective strategies, and social strategies). The memory strategies subscale assesses the strategies used by learners to store and retrieve new linguistic material (9 items, e.g., "I use new English words in a sentence so I can remember them."). The cognitive strategies subscale assesses the strategies used by learners to better understand and produce English (14 items, e.g., "I try to talk like native English speakers."). The compensation strategies subscale assesses the strategies used by learners to overcome their deficiencies in English competence (6 items, e.g., "To understand unfamiliar English words, I make guesses."). The metacognitive strategies subscale measures the strategies applied by learners to monitor and control their cognition (9 items, e.g., "I notice my English mistakes and use that information to help me do better."). The affective strategies subscale measures the strategies applied by learners to regulate their emotion, motivation, and attitudes (5 items, e.g." "I try to relax whenever I feel afraid of using English."). The social strategies subscale measures the strategies applied by learners to interact with others through English (6 items, e.g., "I practice English with other students.")

In all instances, the participants use a 5-point Likert scale to indicate the extent to which they endorse the Chinese SILL question items, ranging from 1 (I never do this) to 5 (I always do this). The Chinese SILL demonstrated satisfactory internal consistency with a sample of 505 Taiwanese university EFL students, with Cronbach's alpha $=0.94$ (Yang 1992), comparable to that of the original SILL whose Cronbach's alphas were reported to range from 0.85 to 0.95 (Oxford and Burry-Stock 1995). In the present study, the internal consistency of the SILL was 0.93, suggesting that the Chinese version of the SILL was a valid and reliable instrument. 


\subsection{Achievement Measure}

The achievement measure was interpreting students' semester grades in MandarinEnglish interpreting classes. The course grade was chosen as an overall measure of the students' interpreting achievement because it has been used as a global measure of students' learning achievement in both SLA research (e.g., Lan and Oxford, 2003; Frantzen and Magnan 2005) and interpreting research (e.g., Chiang 2010).

\subsection{Data Collection and Analysis Procedure}

The data were collected through a set of questionnaires that consisted of a background information questionnaire and Yang's (1992) Chinese version of the SILL. The questionnaires were administered by the course instructors to the students during one of their regular class meetings. After the questionnaires were completed, the instructors collected the questionnaires and sent them back to the researcher for data analysis. Descriptive statistics and Pearson product-moment correlation analyses were performed to analyze the data. In addition, Oxford's (1990) key to understanding mean scores on the 5-point Likert-type SILL was used to construe the results: 1) high use $=3.5$ to $5.0 ; 2$ ) medium use $=2.5$ to $3.4 ; 3$ ) low use $=1.0$ to 2.4 .

\section{Results}

\subsection{Trends and Patterns of English Learning Strategies of Interpreting Students}

The results of descriptive statistics showed that interpreting students employed overall English learning strategies at a medium frequency $(M=3.14, S D=0.44)$. They also reported using both indirect strategies $(M=3.24, S D=0.54)$ and direct strategies $(M=3.07, S D=0.40)$ at a medium frequency level, although the former was employed slightly more frequently than the latter.

Similar results were found when the six subscales of the SILL were analyzed. Table 1 presents the results.

TABLE 1

Means and Standard Deviations of the Six SILL Subscales

\begin{tabular}{|l|c|c|c|c|}
\hline Strategy Type & $\boldsymbol{M}$ & SD & Use & Ranking \\
\hline Compensation & 3.40 & 0.52 & Medium & 1 \\
\hline Social & 3.27 & 0.64 & Medium & 2 \\
\hline Metacognitive & 3.26 & 0.62 & Medium & 3 \\
\hline Affective & 3.18 & 0.60 & Medium & 4 \\
\hline Cognitive & 2.98 & 0.46 & Medium & 5 \\
\hline Memory & 2.98 & 0.48 & Medium & 5 \\
\hline
\end{tabular}

As shown in Table 1, all of the six types of learning strategies were employed within the medium frequency of use (2.5 to 3.4). Reaching the upper limit of medium strategy use, compensation strategies were the most frequently used strategies, followed by social strategies (second), metacognitive strategies (third), and affective 
strategies (fourth). Coincidentally, cognitive strategies and memory strategies had the same mean $(M=2.98)$ and tied for the lowest ranking.

After analyzing the use of individual strategy items for this group of interpreting students, it was found that 10 strategies reached the frequency of high use. Table 2 displays the means and standard deviations of these highly used individual strategies.

TABLE 2

Individual Strategies with Means Reaching High Use

\begin{tabular}{|c|c|c|c|c|}
\hline Type & Item Description & $M$ & $S D$ & Ranking \\
\hline COM & $\begin{array}{l}\text { 29. If I can't think of an English word, I use a word or phrase } \\
\text { that means the same thing. }\end{array}$ & 3.84 & 0.735 & 1 \\
\hline $\mathrm{COM}$ & 24. To understand unfamiliar English words, I make guesses. & 3.80 & 0.739 & 2 \\
\hline COG & 12. I practice the sounds of English. & 3.73 & 0.835 & 3 \\
\hline MET & 33. I try to find a better way to learn English. & 3.73 & 0.775 & 4 \\
\hline MET & 32. I pay attention when someone is speaking in English. & 3.70 & 0.784 & 5 \\
\hline COG & 11. I try to talk like a native English speaker. & 3.58 & 0.910 & 6 \\
\hline COG & $\begin{array}{l}\text { 21. I find the meaning of an English word by dividing it into } \\
\text { parts that I understand. }\end{array}$ & 3.57 & 0.842 & 7 \\
\hline COG & $\begin{array}{l}\text { 15. I watch TV shows or movies spoken in English or listen } \\
\text { to English radio programs. }\end{array}$ & 3.57 & 0.897 & 8 \\
\hline COG & 10. I say or write new English words several times. & 3.56 & 0.876 & 9 \\
\hline SOC & 49. I try to learn about the culture of English speakers. & 3.51 & 0.921 & 10 \\
\hline
\end{tabular}

Note: $\mathrm{MEM}=$ memory strategy; $\mathrm{COG}=$ cognitive strategy $; \mathrm{COM}=$ compensation strategy ; $\mathrm{MET}=$ metacognitive strategy $; \mathrm{AFF}=$ affective strategy $; \mathrm{SOC}=$ social strategy

As presented in Table 2, both the first ranked strategy and the second ranked strategy were compensation strategies: They were item 29 "If I can't think of an English word, I use a word or phrase that means the same thing" and item 24 "To understand unfamiliar English words, I make guesses," respectively. The other highuse strategies were five cognitive strategies, including trying to talk like a native speaker of English, practicing English sounds, finding the meanings of English words by dividing them into understandable parts, watching English TV shows or movies or listening to English radio programs, and saying or writing new words several times; two metacognitive strategies, including trying to find a better way to learn English and paying attention when someone was speaking English; and one social strategy: trying to learn about the culture of English speakers. No individual memory strategies and affective strategies were in high use. In fact, the only individual strategy that fell into the low use was a memory strategy: Item 6 "I use flashcard to remember new English words" $(M=2.29, S D=0.997)$.

\subsection{Correlations between Learning Strategies and Interpreting Achievement}

\subsubsection{Correlations between Overall SILL, Two Strategy Classes and Achievement}

Table 3 displays the results regarding the correlations between overall strategy use, direct strategies, indirect strategies, and semester grades. 
TABLE 3

Correlations between Overall SILL, Two Strategy Classes and Achievement

\begin{tabular}{|l|c|c|c|c|}
\hline & Grades & Overall SILL & Direct Strategies & Indirect Strategies \\
\hline Grades & 1 & $0.293^{* *}$ & $0.308^{* *}$ & $0.246^{\star}$ \\
\hline Overall SILL & & 1 & $0.952^{* *}$ & $0.946^{* *}$ \\
\hline Direct Strategies & & & 1 & $0.801^{* *}$ \\
\hline Indirect Strategies & & & & 1 \\
\hline
\end{tabular}

Note: ${ }^{* *} \mathrm{p}<0.01$ (2-tailed). ${ }^{*} \mathrm{p}<0.05$ (2-tailed).

As shown in Table 3, both the overall SILL and its two strategy classes (direct and indirect strategies) were significantly and positively related to interpreting achievement as measured by semester grades. Overall English strategy use had a small correlation with interpreting achievement $(r=0.293, p<0.01)$. Direct strategies had a moderate correlation with achievement $(r=0.308, p<0.01)$, whereas indirect strategies had a small correlation with achievement $(r=0.246, p<0.05)$.

\subsubsection{Correlations between the SILL's Six Strategy Groups and Achievement}

Table 4 presents the findings concerning the associations between the SILL's six subscales and semester grades.

TABLE 4

Correlations between the SILL's Six Subscales and Achievement

\begin{tabular}{|l|c|c|c|c|c|c|c|}
\hline & Grades & MEM & COG & COM & MET & AFF & SOC \\
\hline Grades & 1 & 0.091 & $0.379^{* *}$ & $0.234^{*}$ & $0.282^{* *}$ & 0.190 & 0.146 \\
\hline MEM & & 1 & $0.601^{* *}$ & $0.389^{* *}$ & $0.566^{* *}$ & $0.449^{* *}$ & $0.503^{* *}$ \\
\hline COG & & & 1 & $0.496^{* *}$ & $0.780^{* *}$ & $0.566^{* *}$ & $0.698^{* *}$ \\
\hline COM & & & & 1 & $0.461^{* *}$ & $0.505^{* *}$ & $0.415^{* *}$ \\
\hline MET & & & & & 1 & $0.674^{* *}$ & $0.684^{* *}$ \\
\hline AFF & & & & & & 1 & $0.605^{* *}$ \\
\hline SOC & & & & & & & 1 \\
\hline
\end{tabular}

Note: $\mathrm{MEM}=$ memory strategy $\mathrm{COG}=$ cognitive strategy; $\mathrm{COM}=$ compensation strategy ;

$\mathrm{MET}=$ metacognitive strategy $; \mathrm{AFF}=$ affective strategy $; \mathrm{SOC}=$ social strategy; ${ }^{* *} \mathrm{p}<0.01$ (2-tailed); ${ }^{*} \mathrm{p}<0.05$ (2-tailed).

As displayed in Table 4, three strategy groups were significantly and positively related to semester grades, including two direct strategy groups (cognitive and compensation strategies) and one indirect strategy group (metacognitive strategies). Cognitive strategies had a moderate correlation with semester grades $(r=0.379$, $p<0.01$ ), whereas compensation strategies had a small correlation with interpreting achievement $(r=0.234, p<0.05)$. Metacognitive strategies also had a small correlation with interpreting achievement $(r=0.282, p<0.01)$.

\subsubsection{Correlations between Individual SILL Items and Achievement}

Table 5 displays the SILL items that were significantly related to achievement. 
TABLE 5

Individual Strategies with Significant Correlations with Achievement

\begin{tabular}{|c|c|c|}
\hline Item Description & Type & $\begin{array}{l}r \text { with } \\
\text { Grades }\end{array}$ \\
\hline 11. I try to talk like a native English speaker. & COG & $0.469^{* *}$ \\
\hline 14. I start conversations in English. & COG & $0.398^{\star *}$ \\
\hline 31. I notice my English mistakes and use that information to help me do better. & MET & $0.398^{* *}$ \\
\hline 12. I practice the sounds of English. & COG & $0.383^{\star *}$ \\
\hline 18. I try to think in English. & COG & $0.368^{* *}$ \\
\hline 2. I use new English words in a sentence so I can remember them. & MEM & $0.306^{* *}$ \\
\hline 36. I look for opportunities to read as much as possible in English. & MET & $0.305^{\star *}$ \\
\hline 37. I have clear goals for improving my English. & MET & $0.303^{* *}$ \\
\hline 40. I encourage myself to speak even when I am afraid of making a mistake. & AFF & $0.300^{* *}$ \\
\hline 39. I try to relax whenever I feel afraid of using English. & AFF & $0.256^{\star *}$ \\
\hline 30. I try to find as many ways as I can to use my English. & MET & $0.247^{\star}$ \\
\hline $\begin{array}{l}\text { 25. When I can't think of a word during a conversation in English, I use } \\
\text { gestures. }\end{array}$ & $\mathrm{COM}$ & $0.237^{\star}$ \\
\hline 24. To understand unfamiliar English words, I make guesses. & $\mathrm{COM}$ & $0.226^{\star}$ \\
\hline 16. I read for pleasure in English. & COG & $0.220^{*}$ \\
\hline 49. I try to learn about the culture of English speakers. & SOC & $0.220^{*}$ \\
\hline $\begin{array}{l}\text { 29. If I can't think of an English word, I use a word or phrase that means the } \\
\text { same thing. }\end{array}$ & $\mathrm{COM}$ & $0.214^{*}$ \\
\hline 22. I try not to translate word for word. & COG & $0.213^{*}$ \\
\hline 38. I think about my progress in learning English. & MET & $0.208^{*}$ \\
\hline 17. I write notes, messages, letters, or reports in English. & COG & $0.203^{*}$ \\
\hline 23. I make summaries of information that I hear or read in English. & COG & $0.197^{*}$ \\
\hline 28. I try to guess what the other person will say next in English. & $\mathrm{COM}$ & $0.194^{*}$ \\
\hline
\end{tabular}

Note: $\mathrm{MEM}=$ memory strategy; $\mathrm{COG}=$ cognitive strategy; $\mathrm{COM}=$ compensation strategy ; $\mathrm{MET}=$ metacognitive strategy $; \mathrm{AFF}=$ affective strategy $; \mathrm{SOC}=$ social strategy. ${ }^{*} \mathrm{p}<0.01$ (2-tailed). ${ }^{*} \mathrm{p}<0.05$ (2-tailed).

Twenty-one individual strategies (around 43\% of the SILL items) were significantly and positively related to semester grades. Consistent with the earlier results that found that cognitive, metacognitive, and compensation strategies were the only three strategy categories related to semester grades, most of these individual strategies related to semester grades were from these three strategy groups, including eight cognitive strategies, five metacognitive strategies, four compensation strategies. The exceptions were items 39 and 40, which were affective strategies; item 2, which was a memory strategy; and item 49 , which was a social strategy (item 49). Among these 21 individual strategies, nine strategies had moderate correlations with interpreting achievement, whereas 12 strategies had small correlations with achievement.

\section{Discussion}

\subsection{Trends and Patterns of English Learning Strategies of Interpreting Students}

The overall mean strategy use of interpreting students in this study $(M=3.14)$ was similar to the findings among regular EFL students in other settings: It was lower 
than that in Nisbet's (2002) study on EFL students in the People's Republic of China $(M=3.45)$ and Park's (1994) study on Korean EFL students $(M=3.21)$, but higher than Bremner's (1999) study on Hong Kong EFL students $(M=2.99)$ and Lai's (2009) study on Taiwanese non-English majors $(M=2.84)$. This finding that the frequency of learning strategies utilized by interpreting students did not differ from those of regular EFL students was surprising, given the demand of interpreting on English proficiency was much higher than the demand of regular communication on English competence.

Regarding the SILL's six subscales, similar results were observed. All of the six types of learning strategies were employed within the 2.5 to 3.4 medium frequency, suggesting that this sample of interpreting students sometimes used the six categories of learning strategies to learn English. These findings were in line with Oxford's (1992) comparative analysis of 10 large-scale SILL studies, which found that whereas typical second language learners reported frequently using an average of 3.7 of the six SILL categories, typical foreign language learners reported frequently using an average of less than one of the six strategy categories. Perhaps in an EFL learning environment like Taiwan, interpreting students and regular students were alike in their responses to the inherent constraints of their EFL learning environment: That is, both groups of students had limited exposure to English language outside of English classes and were not as compelled to employ more strategies to communicate in the English language as were ESL students in the US or in other ESL contexts in which English is essential for daily survival; this inherent difference, hence, resulted in their relatively low frequency of strategy use.

Of the six strategy types, compensation strategies were the most frequently used strategies by the students; they reached the upper limit of medium strategy use $(M=3.4)$. The result aligned with those of several studies on regular Taiwanese EFL students, including Lai's (2009) survey of college freshmen, Liu's (2004) study of senior high school students, and Lan and Oxford's (2003) study of elementary school students. These findings seemed to support a growing body of evidence that preferences for particular types of L2 learning strategies seem to be culture-specific (Chamot 2005; O’Malley and Chamot 1990; Oxford 1989; 1995). In the case of Taiwanese EFL students, they seem to be most inclined to use compensation strategies to help them overcome their deficiencies in English, regardless of their educational level and whether they were interpreting students or not.

This explanation was further corroborated by the analyses of the individual SILL items. Both the top ranked strategy and the second ranked strategy were compensation strategies whose frequency of use surpassed Oxford's threshold of high strategy use: The top ranked item 29 "If I can't think of an English word, I use a word or phrase that means the same thing" had a mean of 3.84, whereas the second ranked item 24 "To understand unfamiliar English words, I make guesses" had a mean of 3.80. The results suggested that interpreting students relied highly on paraphrasing and guessing to compensate for the gaps in their ability to produce and comprehend English.

As for the other highly used individual strategies, several strategies deserved special attention. For instance, the strategy of watching TV programs, movies, or listening to radio programs was not only frequently used by this sample of undergraduate interpreting students to improve their English, but it was also one of the 
most popular strategies used by postgraduate Mandarin-English conference interpreting trainees to improve their English proficiency according to Chang and Wu's (2011) study. Based on their findings from the open-ended question, Chang and $\mathrm{Wu}$ (2011) concluded that their participants used more receptive-skills-oriented activities than productive-skills-oriented strategies to improve their oral proficiency. However, if a standardized measurement instrument, rather than an open-ended question, had been used in their study, the results might have been different. As found in this study (Table 2), this sample of interpreting students also frequently used many strategies to improve their productive skills, including speaking, such as items 11 "I try to talk like a native English speaker," 12 "I practice the sounds of English," 10 "I say or write new English words several times," and 29 - the most frequently used strategy - "If I can't think of an English word, I use a word or phrase that means the same thing." On the other hand, the SILL seemed to need further modification before it could completely tap into the entire repertoire of interpreting students' L2 learning strategies. For instance, Chang and Wu (2011) found that shadowing - the same commonly-used pre-simultaneous-interpreting activity which enables trainees to listen and speak at the same time - was used by six conference interpreting trainees to improve their English proficiency, but shadowing was not listed on the SILL. As a result, it was impossible to determine whether, and to what extent, shadowing was used as an English learning strategy by this sample of interpreting students. Future studies using the SILL or other similar instruments to examine interpreting students' L2 learning strategies should include shadowing as one of the learning strategies in their measurement instrument.

As for the least frequently used strategy group, cognitive strategies and memory strategies tied for the lowest ranking with the same mean $(M=2.98)$. The results were similar to two studies involving college freshmen in Taiwan: Lai (2009) found that affective strategies and memory strategies ranked $6^{\text {th }}$ and $5^{\text {th }}$, respectively, whereas Klassen (1994) reported that memory strategies and cognitive strategies ranked $6^{\text {th }}$ and $5^{\text {th }}$, respectively. Despite the minor differences in the ranking, the findings of these studies seemed to point to the same conclusion that memory strategies were infrequently used among Taiwanese students. However, these findings were counterintuitive, as ethnic Chinese EFL students are commonly believed to rely heavily on memory skills to learn English. These counterintuitive findings seem to support some researchers' view that the memory strategies listed on the SILL might not be effective in tapping into all of the memories strategies used by ethnic Chinese EFL students (Goh and Kwah 1997; Lai 2009), including the Taiwanese interpreting students participating in this study.

\subsection{Relationship between English Learning Strategies and Interpreting Achievement}

Interpreting students' English learning strategies were found to have significant positive associations with Mandarin-English interpreting achievement, no matter how the SILL was analyzed. These results were generally congruent with the findings of many strategy studies that reported significant positive correlations between overall strategy use and L2 performance among regular L2 learners (for reviews, see Oxford 1995; 2004), but there were some differences at different levels of the SILL. 
The following section will further discuss the similarities and differences in terms of the SILL's subscales and individual strategy items.

Three of the six SILL subscales were found to have significant positive correlations with interpreting achievement, including cognitive strategies, compensation strategies, and metacognitive strategies. The cognitive strategy group had a significant moderate association with the interpreting students' achievement $(r=0.379, p<0.05)$. This finding echoed the results of many studies that found a significant positive correlation between cognitive strategies and L2 performance among regular L2 learners. For instance, Ehrman and Oxford (1995) reported that the cognitive strategy group was the only SILL group that was significantly correlated with one of their proficiency ratings in their study among regular L2 learners of a wide range of target languages in an intensive language program in the USA $(r=0.21, \mathrm{p}<0.02)$. The convergent findings that the cognitive strategy group was a significant correlate of language performance in both studies suggested that cognitive strategies played as much a vital role in the achievement of interpreting students as in that of regular L2 learners.

Notwithstanding this resemblance, some subtle differences in the cognitive strategies that were related to language performance in both studies should be noted. The cognitive strategy group includes both a practice and a deep processing component, but Ehrman and Oxford (1995) suggested that the deep processing component might be more important in their participants' language proficiency than the practice component, because an effort measure in their study was not related to proficiency. However, the deep processing component alone could not totally explain the significant relationship between cognitive strategy group and interpreting students' achievement, as results of the individual strategy analyses showed that several items measuring the strategies of practicing English both formally and naturalistically were significantly and positively associated to interpreting achievement, such as items 11, 12,14 , and 23. That is, both the practice component and the deep processing component of the cognitive strategy group played significant roles in interpreting students' achievement. Perhaps this subtle difference found in the present study indicated that the students who were more likely to succeed in Mandarin-English interpreting classes were those students who most frequently practiced English both formally and naturalistically, while regularly analyzing and synthesizing English learning materials.

The other direct strategies that were significantly and positively related to the interpreting students' semester grades were compensation strategies. The significant positive relationships between the compensation strategy group and semester grades suggested that the more frequently interpreting students employed compensation strategies, the higher their semester-end achievement, or vice versa. Similar to the results of previous studies on regular L2 learners (Bremner 1999; Oxford and Ehrman, 1995), perhaps the current finding indicated that the consecutive interpreting curricula did pose some challenges to these learners, and only those who had more flexibility and resourcefulness to compensate for their English deficiencies and meet the task demands would excel in the consecutive interpreting classes. Specifically, as the results of the individual strategy analyses have shown, those interpreting students with higher semester grades were those who more frequently employed strategies to overcome their language limitations by using body language (item 25), guessing from context (item 24), anticipating what the other person would say next 
(item 28) or using words or phrases with the same meanings (item 29). These findings echoed the results of several experimental studies on interpreting aptitude that found that associational and expressional fluencies as measured by synonym tests significantly correlated with interpreting performance (e.g., Gerver, Longley, et al. 1989; Russo and Salvador 2004). Together, these findings suggested that the ability to paraphrase might be an integral part of interpreting aptitude.

The metacognitive strategy group was also significantly and positively associated with semester grades, suggesting that the more frequently the interpreting students employed metacognitive strategies to facilitate their English learning, the higher their semester-end achievement, and vice versa. This finding was in line with the numerous similar findings that have been reported in the literature on regular L2 learners: More frequent use of metacognitive strategies is one of the major characteristics that distinguish more successful learners from their less successful peers (e.g., Dreyer and Oxford 1996; Lai 2009; Reiss 1983). In other words, like the more proficient regular L2 learners, those interpreting students with higher semester grades were those who more frequently evaluated their progress in English learning (item 38), had clear goals for improving English (item 37), maximized their opportunities to learn and use English (items 30 and 36), and monitored their mistakes in English for further improvement (item 31). Thus, the current findings suggested that metacognitive strategy use played as much of a role in interpreting students' successes in consecutive interpreting classes as it did in regular L2 learners' successes in regular L2 classes.

In contrast, the memory strategy group was found to have no relationship with semester grades. This finding was different from Kato's (1996, cited in Oxford 2004) finding that memory strategies were related to L2 proficiency in a course focusing on memorizing large numbers of Kanji characters. The reason for the different results might be that the memory strategies listed on the SILL were concerned mostly with strategies used for memorizing vocabulary and structures in the early stages of English learning, such as using rhymes or flashcards; therefore, when the focus of the course was on memorizing Kanji characters, a significant positive correlation between memory strategies and L2 proficiency was found, but when the course was devoted to higher levels of language processing and performance, such as interpreting, the association between memory strategies and language performance dissipated. Thus, the current finding seemed to affirm Oxford's (2004) view that the utility of memory strategies in predicting language performance decreases as the learners become more proficient. Nonetheless, it should be noted that one individual memory strategy did have a significant positive relationship with interpreting achievement (item 2 "I use new English words in a sentence so I can remember them"), suggesting that not all memory strategies were irrelevant to interpreting performance.

In terms of social strategies, the social strategy group was found to have a nonsignificant positive relationship with interpreting students' achievement. This finding was different from Dreyer and Oxford's (1996) study and Oxford and Erhman's (1995) study, both of which found a significant positive relationship between social strategies and L2 proficiency. However, it was in line with Watanabe's (1990) finding that social strategies were not related to Japanese EFL students' self-ratings of English proficiency. Although the social strategy group was not associated with interpreting achievement, one individual social strategy did have a significant positive correlation with interpreting achievement (item 49 "I try to learn about the culture of English 
speakers). This finding seemed to affirm that interpreting was more than just interlingual substitution, i.e., those students who were more actively developing their cultural understanding about English speakers were more likely to receive higher semester grades in Mandarin-English interpreting classes than their less active peers. It seemed that of the three sets of social strategies on the SILL, asking questions and cooperating with others were less relevant to interpreting achievement than was empathizing with others.

In terms of the affective strategy group, it was found to have a positive but nonsignificant relationship with the interpreting students' semester-end achievement. This result was different from studies that reported a significant positive association between affective strategies and regular L2 learners' proficiency (e.g., Dreyer and Oxford 1996; Erhman and Oxford, 1995). However, it resembled Watanabe's (1990) finding that the affective strategy group had no relationship with Japanese EFL students' self-ratings of English proficiency. These divergent results were hard to explain; they perhaps indicated that the effectiveness of affective strategies varied widely depending on the persons involved, the demands of the task and the learning environment. Nevertheless, two individual affective strategies (items 39 and 40) were significantly and positively associated with semester grades, suggesting that the strategies used by interpreting students to lower their foreign language anxiety and overcome their fear about making mistakes did have some bearing on their interpreting achievement. This result echoed both Chiang's (2010) finding that foreign language (English) anxiety had a negative correlation with Mandarin-English interpreting achievement and Bontempo and Napier's (2011) finding that emotional stability (anxiety and neuroticism) was a significant predictor of signed interpreters' self-rated interpreting competence. These results suggested that the ability to contain anxiety in general, and foreign language anxiety in particular, was a part of interpreting aptitude which could effectively discriminate between more and less successful interpreting students.

The present study's findings regarding interpreting students' foreign language learning strategy use and achievement eventually raised the issue as to whether interpreting students' English learning strategy use was a cause or an effect of their consecutive interpreting achievement. It was likely that foreign language learning strategies were both a cause and an effect of interpreting achievement, as SLA researchers have suggested regarding the relationship between L2 learning strategies and L2 proficiency (e.g., McIntyre 1994; Green and Oxford 1995). That is, the relationship between L2 learning strategies and interpreting achievement should be

[...] best visualized not as a one-way arrow leading from cause to effect, but rather as an ascending spiral in which actively used strategies help students attain higher proficiency (here, interpreting achievement), which in turn makes it more likely that students will select these actively used strategies. (Green and Oxford 1995: 288)

The ascending spiral of bi-directional cause and effect between L2 learning strategies and interpreting achievement should also apply to the relationship between interpreting learning strategies and interpreting achievement; axiomatically, the strengths of association between interpreting learning strategies and interpreting achievement should be much stronger than those found between L2 learning strategies and interpreting achievement as reported in the present study. Unfortunately, 
there has been no validated instrument specifically designed to measure interpreting learning strategies. Before a validated interpreting learning strategies measurement instrument is developed, the above speculations about the relationship between interpreting learning strategies and interpreting achievement will remain only speculations which have yet to be substantiated.

\section{Conclusion}

In light of the absence of interdisciplinary research on L2 learning strategies and interpreting, this study initiated an interdisciplinary dialogue between these two fields of study and yielded a fresh set of empirical data regarding the relationship between Taiwanese interpreting students' foreign language (English) learning strategies and their Mandarin-English consecutive interpreting achievement. These findings have important implications for pedagogy and future research.

\subsection{Pedagogical Implications}

In terms of pedagogy, as interpreting students' semester-end achievement was significantly linked to their English learning strategies, teachers are strongly encouraged to provide L2 learning strategy training to interpreting students. To maximize the effectiveness of learning strategy instruction, teachers should first know the strategies used by their students. Many assessment tools are available for detecting students' learning strategies, such as self-report surveys, observations, interviews and learner journals. Instructors are encouraged to consult Cohen and Scott's (1996) analyses regarding the advantages and disadvantages of each of these assessment tools, so that they can determine which assessment tool best meets their needs.

It is particularly important for teachers to help less successful students to acquire three types of learning strategies. These are cognitive strategies, compensation strategies, and metacognitive strategies. Furthermore, students need some individual learning strategies other than the three types of strategies, as these strategies were found to relate to interpreting achievement. Specifically, instructors should teach students how to manipulate the L2 material directly through analyzing, note-taking, summarizing, synthesizing, outlining, and practicing (both formally and informally). Regarding compensatory strategies, teachers should assist students in learning how to make up for missing knowledge by guessing from the context to aid in text/speech comprehension, and by using synonyms and circumlocution to aid in text/speech production. As for metacognitive strategies, instructors should assist students in learning how to identify their own learning styles and needs, plan for performing L2 tasks, monitor mistakes, and evaluate the effectiveness of their own learning strategies. In addition, instructors should equip students with strategies for coping with their anxiety about using English, taking risks, deepening understanding about the other culture, and memorizing L2 materials, as these individual learning strategies also positively correlated with interpreting achievement.

Depending on their own situations, instructors can either interweave L2 learning strategies into interpreting classes, or offer a separate learning how to learn course. Either way, instructors are encouraged to consult Chamot and O'Malley (1996)'s CALLA model for instructional ideas: The CALLA model is a type of strategies-based 
instruction for ESL students which encompasses explicit strategy training, academic language advancement, and content area instruction. Instructors can easily adapt the model by changing some of the components to suit the language needs of interpreting students.

\subsection{Limitations and Recommendations for Future Research}

Some inherent limitations to this study must be noted. First, as the present study concerned only Taiwanese interpreting students' English learning strategies and achievement in Mandarin-English consecutive interpreting classes, the results may not be generalized to interpreting students learning different modes of interpreting, such as simultaneous interpreting and sight interpreting. Future studies can examine whether similar results will be found between interpreting students' L2 strategy use and achievement in various types of interpreting courses. Moreover, the present study found only low to moderate correlations between interpreting students' English learning strategies and interpreting achievement, suggesting that foreign language learning strategy use only accounted for a small to moderate amount of variance in interpreting students' achievement. Future studies can examine whether such variables as foreign language proficiency, interpreting leaning strategies, interpreting learning motivation and L2 learning motivation were linked to their achievement. Finally, because the sample of the present study was Taiwanese interpreting students, these findings may not be applicable to interpreting students with different foreign languages as their working languages in other cultural contexts, such as students with Chinese as their foreign language in Spain, or students with French as their foreign language in Japan. Future research can investigate whether Spanish or Japanese interpreting students' foreign language learning strategies are linked to their achievement in Spanish-Chinese, or Japanese-French consecutive interpreting classes.

\section{ACKNOWLEDGMENTS}

The authors wish to thank the students and teachers who participated in this study.

\section{NOTES}

1. Kato, Fumie (1996): Results of an Australian study of strategy use in learning Japanese Kanji characters. Unpublished manuscript. Sydney: University of Sydney.

2. There are two major types of English departments in Taiwanese colleges and universities: English and applied English. Whereas the former usually focuses more on English literature and linguistics, the latter typically places more emphasis on putting English to practical use in various domains such as business and trade. As well as the four basic skills (listening, speaking, reading and writing), interpreting is taught as the fifth language skill in applied English departments (as is translation).

\section{REFERENCES}

Abraham, Roberta. G., and VAnN, Roberta J. (1987): Strategies of two language learners: A case study. In: Anita Wenden and Joan Rubin, eds. Learner Strategies in Language Learning. London: Prentice-Hall International, 85-102.

Bontempo, Karen and NAPIER, Jamina (2011): Evaluating emotional stability as a predictor of interpreter competence and aptitude for interpreting. Interpreting. 13(1):85-105. 
BREMNER, Stephen (1999): Language learning strategies and language proficiency: Investigating the relationship in Hong Kong. Canadian Modern Language Review. 55:490-514.

Снамот, Anna Uhl (2005): Language learning strategy instruction: Current issues and research. Annual Review of Applied Linguistics. 25:112-132.

Снамот, Anna Uhl and O’Malley, J. Michael (1996): Implementing the Cognitive Academic Language Learning Approach (CALLA). In: Rebecca OxFord, ed. Language Learning Strategies Around the World: Cross-cultural Perspectives. Manoa: University of Hawaii Press, 167-174.

Chang, Chia-chien and Schallert, Diane (2007): The impact of directionality on Chinese/ English simultaneous interpreting. Interpreting. 9(2):137-176.

Chang, Chia-chien and Wu, Michelle (2010): From A to A+: The design and implementation of a language enhancement course for Chinese-English interpreting students. English Teaching and Learning. 34(3):85-127.

Chang, Chia-chien and Wu, Michelle (2011): Foreign language needs analysis for conference interpreting trainees. Studies in English Language and Literature. 28:1-24.

CHIANG, Yung-nan (2010): Foreign language anxiety and student interpreters' learning outcomes: Implications for the theory and measurement of interpretation learning anxiety. Meta. 55(3):589-601.

Cohen, Andrew and Scotт, Kimberly (1996): A synthesis of approaches to assessing language learning strategies. In: Rebecca Oxford, ed. Language Learning Strategies Around the World: Cross-cultural Perspectives. Manoa: University of Hawaii Press, 89-106.

Donovan, Clare (2004): European Masters Project Group: Teaching simultaneous interpretation into a B language. Interpreting. 6(2):205-216.

Donovan, Clare (2005): Teaching simultaneous interpretation into B: A challenge for responsible interpreter training. Communication and Cognition. 38(3-4):147-165.

Dreyer, Carisma and Oxford, Rebecca (1996): Prediction of ESL proficiency among Afrikaansspeakers in South Africa. In: Rebecca Oxford, ed. Language Learning Strategies Around the World: Cross-cultural Perspectives. Monoa: University of Hawaii Press, 61-74.

Ehrman, Madeline and Oxford, Rebecca (1995): Cognition plus: Correlates of language learning success. Modern Language Journal. 79:67-89.

Frantzen, Diana and Magnan, Sally (2005): Anxiety and the true-false beginner dynamic in beginning French and Spanish classes. Foreign Language Annals. 38(2):171-190.

Gerver, David., Longley, Patricia, Long, John et al.(1989): Selection test for trainee conference Interpreters. Meta. 34(4):724-735.

Gile, Daniel (1995): Basic Concepts and Models for Interpreter and Translator Training. Amsterdam: John Benjamins.

GiLe, Daniel (2009): Basic Concepts and Models for Interpreter and Translator Training. $2^{\text {nd }}$ ed. Amsterdam: John Benjamins.

GoH, Christine and KwaH, Poh Foong (1997): Chinese ESL students' learning strategies: A look at frequency, proficiency, and gender. Hong Kong Journal of Applied Linguistics. 2:39-53.

Green, John and Oxford, Rebecca (1995): A closer look at learning strategies, L2 proficiency, and gender. TESOL Quarterly. 29:261-297.

KLASSEN, John (1994): The language learning strategies of freshman English students in Taiwan: a case study. Master dissertation, unpublished. Chico: California State University.

Ku, Pei-yu. (1995): Strategies associated proficiency and predictors of strategy choice: A study on language learning strategies of EFL students at three educational levels in Taiwan. Doctoral dissertation, unpublished. Bloomington: Indiana University.

LAI, Ying-chun (2009): Language learning strategy use and English proficiency of university freshmen in Taiwan. TESOL Quarterly. 43(2):255-280.

LAN, Ran and OXFORD, Rebecca (2003): Language learning strategy profiles of elementary school students in Taiwan. IRAL. 41:339-379. 
Lim, Hyang-Ok (2005): Working into the B language: The condoned taboo? Meta. 50(4):online. 19 p. Visited on 6 June 2010, <http://www.erudit.org/revue/meta/2005/v50/n4/019870ar. html? lang=en>.

Lin, Su-hwa (1999): A study of English listening comprehension strategies used by senior high school students in Taiwan. Master dissertation, unpublished. Kaoshiung: National Kaoshiung Normal University.

LiU, Ming-ling (2004): A Study of Beliefs about Language Learning and Learning Strategies of Senior High School Students. Master dissertation, unpublished. Kaoshiung: National Kaoshiung Normal University.

Monti, Christina, Bendazzoli, Claudio, Sandrelli, Annalisa, et al. (2005): Studying directionality in simultaneous interpreting through an electronic corpus: EPIC (European Parliament Interpreting Corpus). Meta. 50(4):online. Visited on 6 June 2010, <http://www. erudit.org/revue/meta/2005/v50/n4/019850ar.pdf>.

Mullins, Premvadee Yampeka (1992): Successful English language learning strategies of students enrolled in the Faculty of Arts, Chulalongkorn University, Bangkok, Thailand. Doctoral thesis, unpublished. San Diego: United States International University.

Naiman, Neil, Frölich, Maria, Stern Hans Heinrich, et al. (1978): The good language learners. Research in Education Serie No. 7. Toronto: Ontario Institute for Studies in Education.

NisBET, Deana L. (2002): Language learning strategies and English proficiency of Chinese university students (Doctoral dissertation, Regent University, 2002). Dissertation Abstract International 63(10):3500A.

O’malley, J. Michael and Снамот, Anna Uhl (1990): Learning Strategies in Second Language Acquisition. Cambridge: Cambridge University Press.

OxFORD, Rebecca (1990): Language Learning Strategies: What Every Teacher Should Know. New York: Newbury House/Harper and Row.

OXFord, Rebecca (2004): Changing the face of EFL instruction through learning styles and strategies. Selected Papers from the $13^{\text {th }}$ International Symposium on English Teaching. Taipei: Crane Publishing Co, i-x.

Oxford, Rebecca and Crookall, David (1989): Research on language learning strategies: methods, findings, and instructional issues. Modern Language Journal. 73:404-419.

Oxford, Rebecca and Ehrman, Madeline. E. (1995): Adults' language learning strategies in an intensive language program in the United States. System. 23:359-386.

Oxford, Rebecca and Nyikos, Martha. (1989): Variables affecting choice of language learning strategies by university students. Modern Language Journal. 73:291-300.

Oxford, Rebecca and Burry-STOCK, Judith (1995): Assessing the use of language learning strategies worldwide with the ESL/EFL version of the strategy inventory for language learning (SILL). System. 23:1-23.

PARK, Gi-Pyo (1994): Language learning strategies and English proficiency in Korean university students. Foreign Language Annals. 30:201-221.

Purpura, James (1997): An analysis of the relationshipsbetwentesttakers'cognitiveand metacognitive strategy use and second language test performance. Language Learning. 42(2):289325

ReIss, Mary-Ann (1983): Helping the unsuccessful learners. Forum. 21:2-24.

Rubin, Joan (1975): What the "good language learner" can teach us. TESOL Quarterly. 9(1): 41-51.

Russo, Mariachiara and Salvador, Pippa (2004): Aptitude to interpreting: Preliminary results of a testing methodology based on paraphrase. Meta. 49(2):409-432.

SETton, Robin (1993): Is non-intra-IE interpretation different? European models and ChineseEnglish realities. Meta. 38(2):238-256.

SETton, Robin (1999): Simultaneous Interpretation: A Cognitive-pragmatic Analysis. Amsterdam/ Philadelphia: John Benjamins.

VANN, Roberta J., and ABRAHAM, Roberta G. (1990): Strategies of unsuccessful learners. TESOL Quarterly. 24:177-198. 
Watanabe, Yoshinori (1990): External variables affecting language learning strategies of Japanese EFL learners. Master dissertation, unpublished. Lancaster: Lancaster University.

WANG, Wen-yin (2001): Effects of gender and proficiency on listening comprehension strategy used by Taiwanese EFL senior high school students: A case from Changhua, Taiwan. Master dissertation, unpublished. Changhua: National Changhua Normal University.

Wu, Michelle (2001): The importance of being strategic: A strategic approach to the teaching of simultaneous interpreting. Studies of Interpretation and Translation. 6:79-92.

YANG, Nae-dong (1992): Second language learners' belief about language learning and their use of learning strategies: A study of college students of English in Taiwan. Doctoral thesis, unpublished. Austin: University of Texas. 